\title{
Three dimensional finite element analyses to evaluate stress distribution around implant retained mandibular over denture using two different attachment systems
}

\begin{abstract}
Statement of the problem: A key factor for the success or failure of dental implants is the manner in which stresses are transferred to surrounding bone.
\end{abstract}

Purpose of the study: The aim of this study was to create complete three-dimensional finite element models of mandibles with their implant-retained over dentures (IRO) to evaluate the influence of two different attachment systems on stress distribution at implant bone level.

Methods: The geometries of six edentulous mandibles with their IRO were generated from computed tomography scans. Two implants $(3.75 \mathrm{~mm} \times 13 \mathrm{~mm})$ with ball abutments and locator attachments were placed in the canine areas of each edentulous mandible. Two models FEM (A) and FEM (B) were used for the load application and analysis. A vertical $(100 \mathrm{~N})$ and oblique $(100 \mathrm{~N})$ loads were applied to each of the above models respectively at the premolar/molar region of the over dentures. These two different models were analyzed by a finite element program (Solid Works) and displayed using Von misses stress patterns.

Results: The results showed that the maximum stress values were seen at the crestal bone around all implants. Lower stress values were recorded for the locator attachment at all measured aspects. Vertical loading was associated with higher stress values and working side implants were showing greater stress magnitudes.

Conclusion: Within the limitations of this study, locator attachment may be an adequate alternative to ball attachment as it reduces stresses on the implant body and supporting structures for implant-retained over dentures.

Clinical implications: No specific single parameter could affect the outcomes of implant over denture. Instead, treatment outcomes are favored when the treatment is based on optimizing all possible parameters.

Keywords: ball attachment, locator attachment, implant-retained over denture, computed tomography, finite
Volume 2 Issue 5 - 2015

\author{
Ahmed M Abdelhamid,' Nazem K Assaad,'² \\ Akram F Neena ${ }^{3}$ \\ 'Professor and Head of Removable Prosthodontics department, \\ Faculty of Dentistry, Alexandria University, Egypt \\ ${ }^{2}$ Assisstant professor of Prosthodontics, Lebanese University, \\ Lebanon \\ ${ }^{3}$ Assistant Lecturer of Removable Prosthodontics, Faculty of \\ Dentistry, Alexandria University, Egypt
}

Correspondence: Akram Fathy Neena,Assistant lecturer of Removable Prosthodontics, Faculty of Dentistry, Alexandria University, Egypt, Tel 201000000000 ,

Email loxinternationa12000@yahoo.com

Received: June 21, 2015 | Published: July 28, 2015
Abbreviations: IRO, implant retained overdenture; FEM, finite element model; CT, Computerized tomography; PMMA, poly methyl meth acrylate

\section{Introduction}

The ability to replace lost teeth with osseo integrated implants has improved the quality of life. ${ }^{1}$ The treatment of fully edentulous mandibles by means of implant-retained over dentures has become a routine therapy because of its relative simplicity, minimal invasiveness, affordability, ease of usage, and its ability to minimize or eliminate movement of the mandibular prostheses. ${ }^{2}$ There is evidence that implant-retained overdentures should be the first choice of treatment for edentulous mandibles. ${ }^{3}$ Many different attachments available today may be used to retain implant-retained over dentures. However, the selected attachment used in implant-retained over denture has a potential effect on implant survival rate, marginal bone loss, soft tissue complications, retention, stress distribution, maintenance complications and patient's satisfaction. ${ }^{4}$ Mandibular implant-retained over dentures connected to two implants with ball attachments have been suggested as the first choice of standard care for edentulous patients. ${ }^{5}$ However, the locator attachment system has been advocated as a suitable alternative to the classical widely used ball attachment because of its low profile design, ease of seating in the oral cavity by the patient, and the self-locating feature to fit nonparallel implants up to $40^{\circ}$ divergence. ${ }^{6}$

A key factor for the success or failure of a dental implant is the manner in which stresses are transferred to surrounding bone which in turn depends on type of loading, the bone implant interface, and shape and characteristics of the implant surface. ${ }^{7}$ Stress induced in dental structures has been studied by different investigative methods 
including mechanical stress analysis, photo-elasticity, and strain measurement on bone surfaces. However, all those methods have certain limitations such as difficulties in modifications after modeling. ${ }^{8}$ Three-dimensional finite element analysis has been viewed as the most suitable tool to evaluate such stresses as it offered several advantages like representation of complex geometries accurately, easy model modifications and representation of the internal state of stress and other mechanical quantities. ${ }^{8}$ Thus, the main goal of the present study was to analyze the influence of two different attachment systems; ball and socket attachment system and locator attachment system, on stress distribution around the implants retaining mandibular over dentures using a three-dimensional finite element analysis.

\section{Materials and methods}

This study was conducted on two precise three-dimensional Finite Element Models [3-D FEM] obtained from six patients attended in the Removable Prosthodontic Department, Faculty of Dentistry, Alexandria University. All patients were selected to have: ${ }^{1}$ undergone implant placement surgery of two screw two-piece similarly designed* implants with the same length $[13 \mathrm{~mm}]$ and width $[3.75 \mathrm{~mm}]$ in the interforaminal region. ${ }^{2}$ Both implants on either sides of each patient's mandible are successfully osseointegrated when assessed clinically and radiographically. ${ }^{3}$ Age of the patients was ranging from 40 to 60 years. ${ }^{4}$ All patients were males, not smokers and free from any intra-oral or systemic diseases. ${ }^{5}$ All patients had acceptable maxillomandibular relationships, sufficient inter-ridge space and $2 \mathrm{~mm}$ even mucosal thickness over implant sites.

\section{Constructing radio-opaque mandibular over dentures}

All six patients participated in this study had received a radioopaque mandibular implant-retained over denture [IRO] (Figure 1) to aid in capturing the CT images from which the FEM will be obtained. The mandibular over denture substitute was constructed following the conventional steps for construction of a complete denture except for packing stage where the trial denture bases as well as the denture teeth were removed out of the flask mould in order to be substituted by a radio-opaque heat-polymerized $\mathrm{PMMA}^{* *}$ which was prepared by adding $10 \%$ Barium Sulphate powder*** to the $90 \%$ polymer powder before mixing it to the liquid monomer.

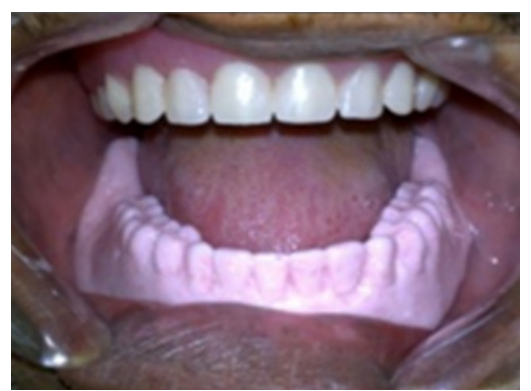

Figure I A radio-opaque mandibular overdenture after construction.

\section{Radiographic imaging}

A high speed multi-slice, low radiation dose, high resolution, threedimensional Computed Tomography $[\mathrm{CT}]^{* * * *}$ was used for accurate determination of bone height, width and to determine implant position and orientation. Trans-axial scans of the mandible were obtained by making slices $1.00 \mathrm{~mm}$ apart through the bone which were stacked by the software to form the three dimensional image. Such an image was then reformatted into coronal [frontal views], cross-sectional [Sagittal views], in addition to the original transverse [axial views]. Two CT scan images were made for every patient: ${ }^{1}$ an image with patient's over denture removed (Figure $2 \mathrm{~A}) .^{2}$ Another image with the radioopaque overdenture in place (Figure $2 \mathrm{~B}$ ).

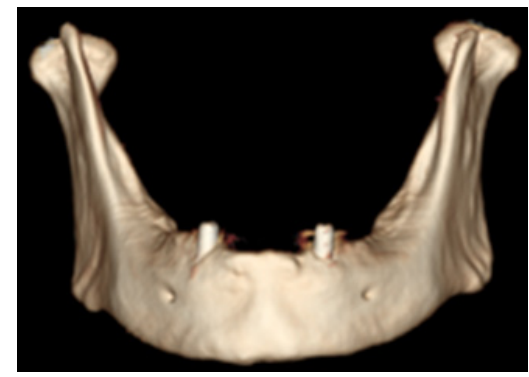

Figure 2A 3D image of a free mandible.

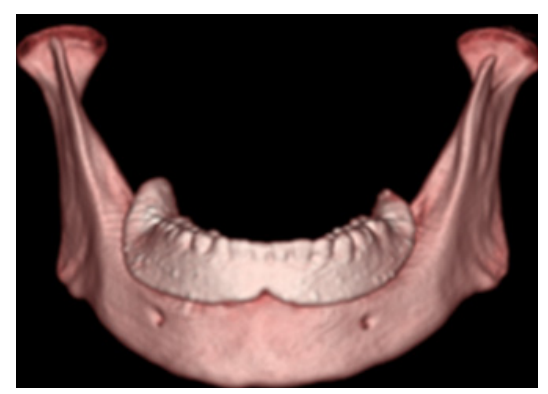

Figure 2B 3D image with overdenture in place.

\section{Methods of finite element analysis}

Modeling: 3D FEM [models that can be accepted by the finite element program] of each implant assembly, its surrounding alveolar bone, the mandibles with their overlying mucosa and overdentures were created to simulate the clinical condition for each patient participated in the study. First, each part of the model was molded as a separate structure following the multi-object reconstruction technique. ${ }^{9}$ Each implant assembly [either ball or locator] was drawn based on accurate dimensions and designs collected from the manufacturer***** using Solid Works finite element program (Figure 3). The mandibles, the overlying mucosa and overdentures were molded using DicoMesher software package ${ }^{10}$ that analyzed data of each CT image axial cut and identified the structures within each image including the bone of the mandible, the overlying mucosa, and the prosthesis. Then, assembly of all parts was carried out in Solid Works to form the FEM (Figure 4). Two FEM were created for each patient: ${ }^{1}$ model [A] an IRO using two Ball and Socket attachments placed over the implants in the interforaminal bone of the patient's edentulous mandible (Figure $5 \mathrm{~A})^{2}$. Model [B] an IRO using two Locator attachments placed over the implants in the interforaminal bone of the patient's edentulous mandible (Figure 5B).
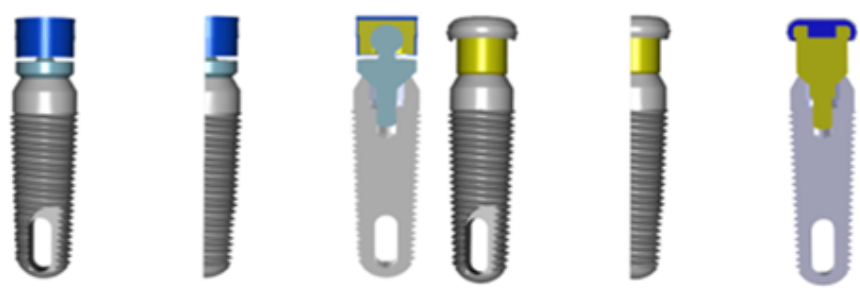

Figure 3 Drawn implant assembly for both attachments. 


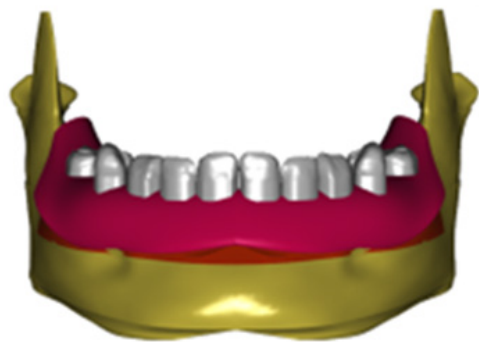

Figure 4 Complete reconstructed FEM.

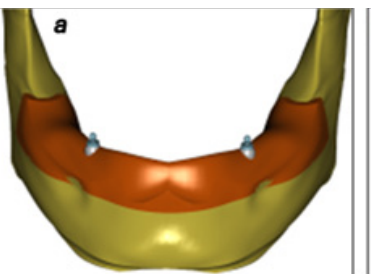

Figure 5A Ball and socket FEM. Figure 5B Locator FEM.

Table I Number of nodes and elements of FEM
Meshing and determination of nodes and elements: The created FEM were then meshed using Dico Mesher software package ${ }^{10}$ (Figure 6). The resulting elements and nodes were numbered by the software program. Number of nodes and elements of each FEM used in this study is shown in Table 1. Each node had 3 degree of freedom [DOF]. Tetrahedral elements were chosen in this study since they are good at meshing arbitrary complex geometries and can match the true displacement function more accurately. ${ }^{10}$

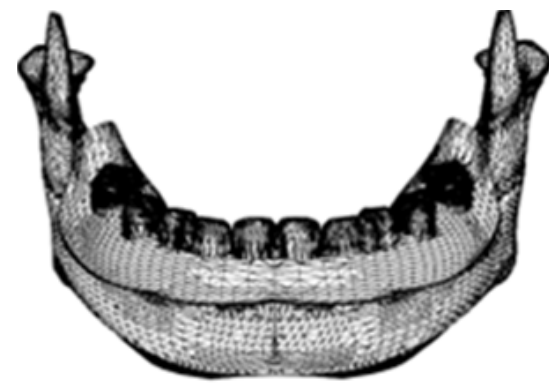

Figure 6 Meshing of a complete FEM.

\begin{tabular}{llllll}
\hline FEM (A) & Nodes & Elements & FEM (B) & Nodes & Elements \\
\hline FEM A-I & 795180 & 562016 & FEM B-I & 796215 & 562361 \\
FEM A-2 & 834939 & 590113 & FEM B-2 & 835974 & 590458 \\
FEM A-3 & 811083 & 573256 & FEM B-3 & 812118 & 573601 \\
FEM A-4 & 783252 & 553,589 & FEM B-4 & 784287 & 553934 \\
FEM A-5 & 771324 & 545155 & FEM B-5 & 772359 & 545500 \\
FEM A-6 & 823011 & 581687 & FEM B-6 & 824046 & 582032 \\
\hline
\end{tabular}

Material properties: Implants were made of Titanium alloy [Ti6Al4V] and both, the Ball and Locator, abutments of grade 4 Titanium. The caps of both attachments were constituted of two components: the metal housing made of Stainless Steel and the resilient component made of nylon rubber. The interforaminal region of the edentulous mandible was composed of a $2 \mathrm{~mm}$ constant cortical bone layer around a cancellous bone core. Elsewhere, bone was assumed to be homogenous. The material properties of bone out of the interforaminal region were deduced by averaging the cancellous and cortical bone properties with assumed proportions of $60 \%$ and $40 \%$ respectively. ${ }^{11,12}$ The overdenture was made of PMMA. Material properties for cortical bone, cancellous bone, mucosa, Titanium parts, rubber and PMMA were taken from literature. All materials were assumed isotropic. The mechanical properties of the materials represented in FEM are presented in Table 2.

Table 2 The material properties of each part of the FEM

\begin{tabular}{llll}
\hline Structural elements & Poisson's ratio & Young's modulus & Reference \\
\hline Cortical bone & 0.3 & 13700 & Barbier et al. ${ }^{13}$ \\
Cancellous bone & 0.3 & 1370 & Barbier et al. ${ }^{13}$ \\
Mucosa & 0.37 & 1 & Menicucci et al. ${ }^{14}$ \\
PMMA & 0.35 & 3000 & Tanino et al. ${ }^{15}$ \\
Ti6Al4V & 0.3 & 135000 & Brunski et al. ${ }^{16}$ \\
Grade 4 titanium & 0.3 & 114000 & Brunski et al. ${ }^{16}$ \\
Stainless steel & 0.31 & 19000 & Barao et al. ${ }^{17}$ \\
Nylon rubber & 0.45 & 5 & Chun et al. ${ }^{18}$ \\
\hline
\end{tabular}

Applying boundary conditions: The forces and the boundary conditions were defined to simulate applied loads and constraints of the structure. Boundary conditions reflect the real situation of the displacement produced at each node. It was defined to simulate the real condition by releasing and restraining some nodes from movement or rotation according to the nature of the 3-D model. In this study, contact was introduced between overdenture and mucosa, and between both parts of the attachments to simulate the interactions existing between 
these bodies. Contact within the attachment assemblies was essential to reproduce the behavior of the two retention mechanisms studied. Implants were considered totally osseointegrated, so a mechanically perfect interface was presumed between implants and bone. Loads of $100 \mathrm{~N} / \mathrm{mm}^{2}$ were applied once vertically and then $20^{\circ}$ obliquely on the center of the right side of the overdenture [premolar/first molar region].

Running the computer program: After specifying the information needed to calculate the stresses in the model using the load of $100 \mathrm{~N}$, Solid Works was used to solve large number of equations simulating the physical properties of the structure being analyzed, the stress distribution pattern around each implant is provided in the form of $3 \mathrm{D}$ static cartoon model made up of the surrounding bone around each dental implant together with the stresses represented by color coded zones; red as maximum and dark blue as minimum (Figure 7-10). The color and size of each zone represents the stresses occurring within [Von Mises patterns].
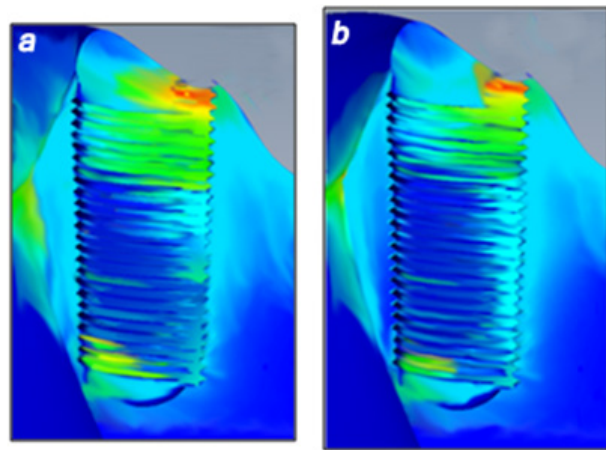

Figure 7A FEMA-I under vertical load.

Figure 7B FEM B-I under vertical load.
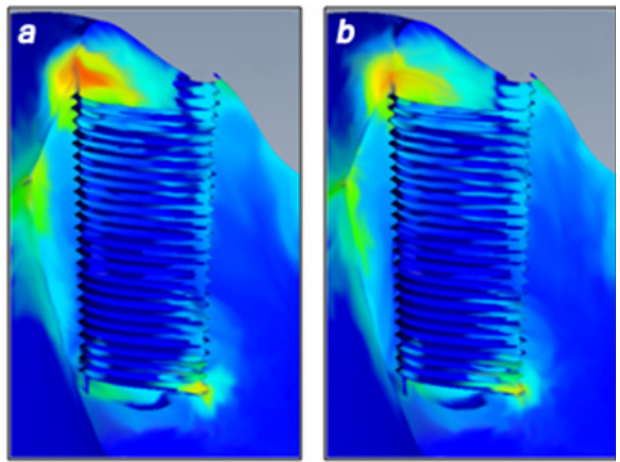

Figure 8A FEM A-I under oblique load.

Figure 8B FEM B-I under oblique load.
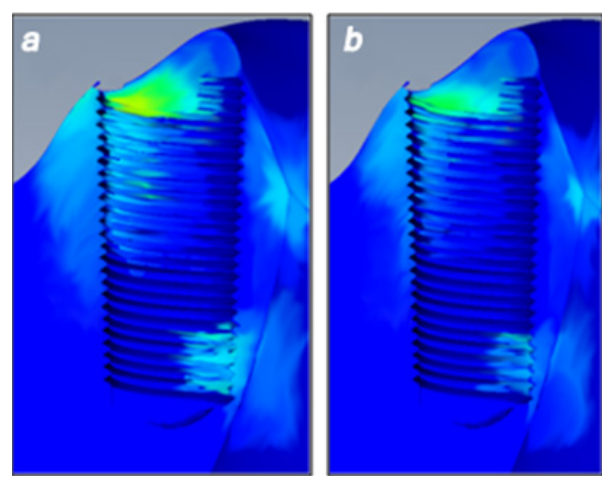

Figure 9A FEMA-I under vertical load. Figure 9B FEM B-I under vertical load.
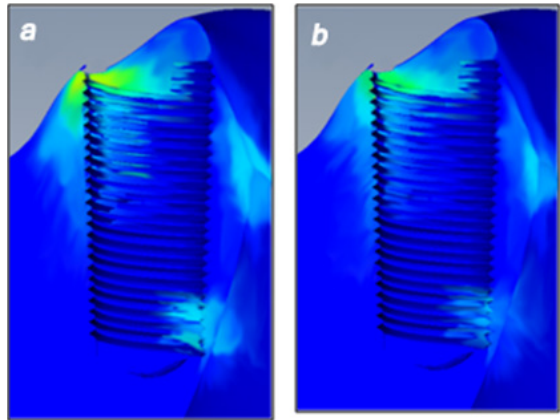

Figure IOA FEM A-I under oblique load.

Figure IOB FEM B-I under oblique load.

\section{Statistical analysis ${ }^{19}$}

Data were fed to the computer and analyzed using IBM SPSS software package version 20.0. ${ }^{20}$ Quantitative data were described using Range [minimum and maximum], mean, standard deviation and median. The distributions of quantitative variables were tested for normality using Kolmogorov-Smirnov test, Shapiro-Wilk test and D'Agstino test and revealed a normally distributed data. Comparison between two independent data was done using independent t-test, while the paired t-test was used to analyze two paired data. Comparison between multiple data was done using ANOVA and Post Hoc test which were assessed using adjusted-Bonferroni. Significance test results were quoted as two-tailed probabilities. Significance of the obtained results was judged at the $5 \%$ level. A p-value of less than 0.05 was considered statistically significant.

\section{Results}

\section{Resulting stresses at the working side implants when loaded by IOON}

For both studied groups, the recorded stresses were highest in value at the crestal bone followed by the apical one, and were found to be least at the lateral walls of the peri-implant bone (Graph 1). There was a statistical significant difference between those stress values recorded at crestal, apical and lateral walls within each studied attachment. The locator attachment showed lower stress values than the ball and socket attachment at all the three sites under study. However, the differences between both attachments were not statistically significant at any of them except when comparing both attachments at the level of the apical and lateral wall under vertical loading only.

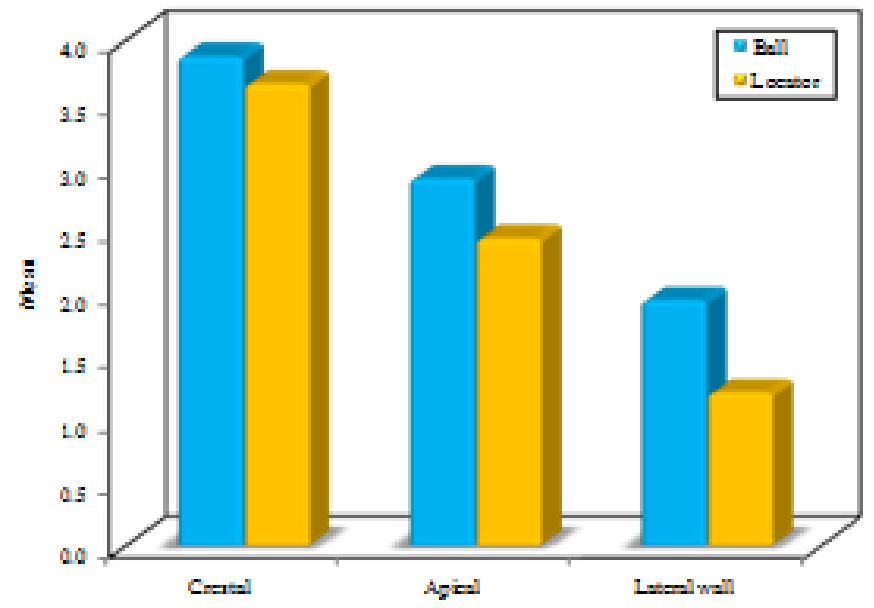

Citation: Abdelhamid AM, Assaad NK, Neena AF.Three dimensional finite element analyses to evaluate stress distribution around implant retained mandibular over denture using two different attachment systems.J Dent Health Oral Disord Ther. 2015;2(5):I7I-178. DOI: 10.15406/jdhodt.20I5.02.00065 


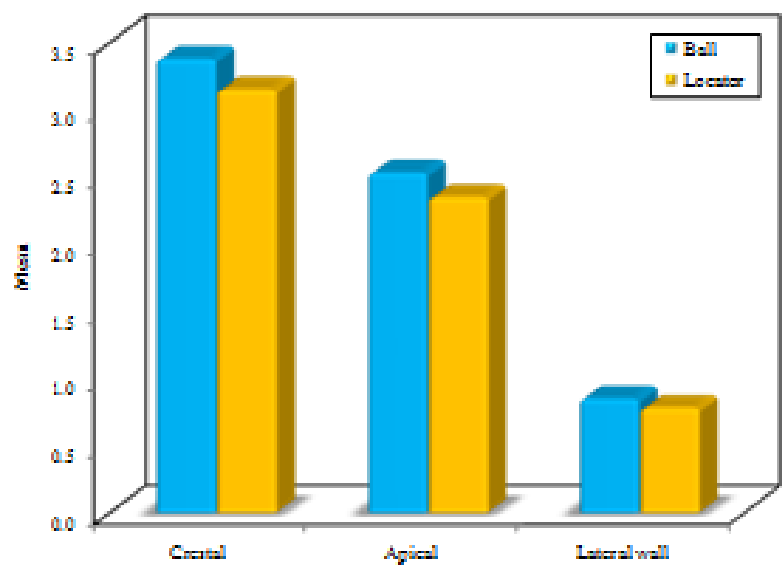

Graph I(a) working side under vertical load. (b) working side under oblique load.

Comparing resulting stresses at working side implants when various load directions were used for both attachment models under study, the recorded stresses were higher when the load was vertical at all measurement sites; crestal, apical, or lateral walls of peri-implant sites (Graph 2); In addition, when comparing vertical to oblique readings, the stress values showed statistically significant differences at all measured sites except for the apical site of the locator attachment.

\section{Resulting stresses at non working side implants when loaded by I00N}
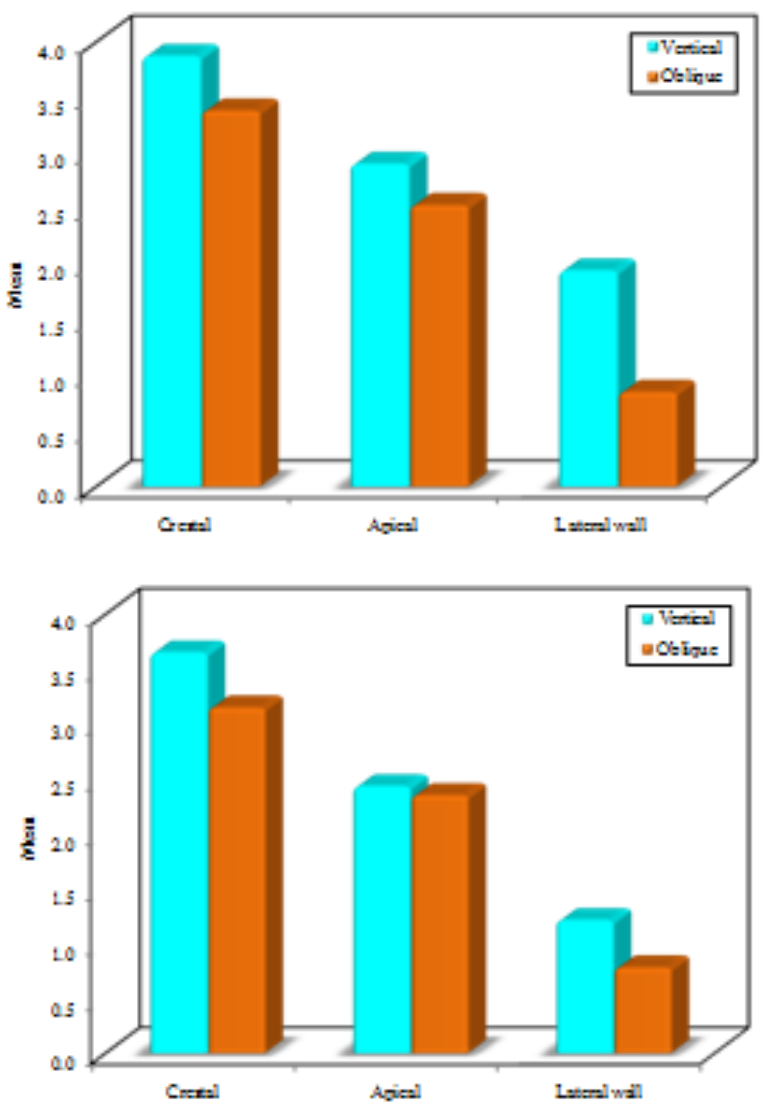

Graph 2 (a) working side of FEM-A. (b) working side of FEM-B.
For both studied groups, the recorded stresses were highest in value at the crestal bone followed by the apical one, and were found to be least at the lateral walls of the peri-implant bone (Graph 3). There was a statistical significant difference between those stress values recorded at crestal, apical and lateral walls for each studied group. When comparing both attachments, the resulting stress values were lower for locator attachment than the ball and socket with a statistical significant difference found at all sites under study.
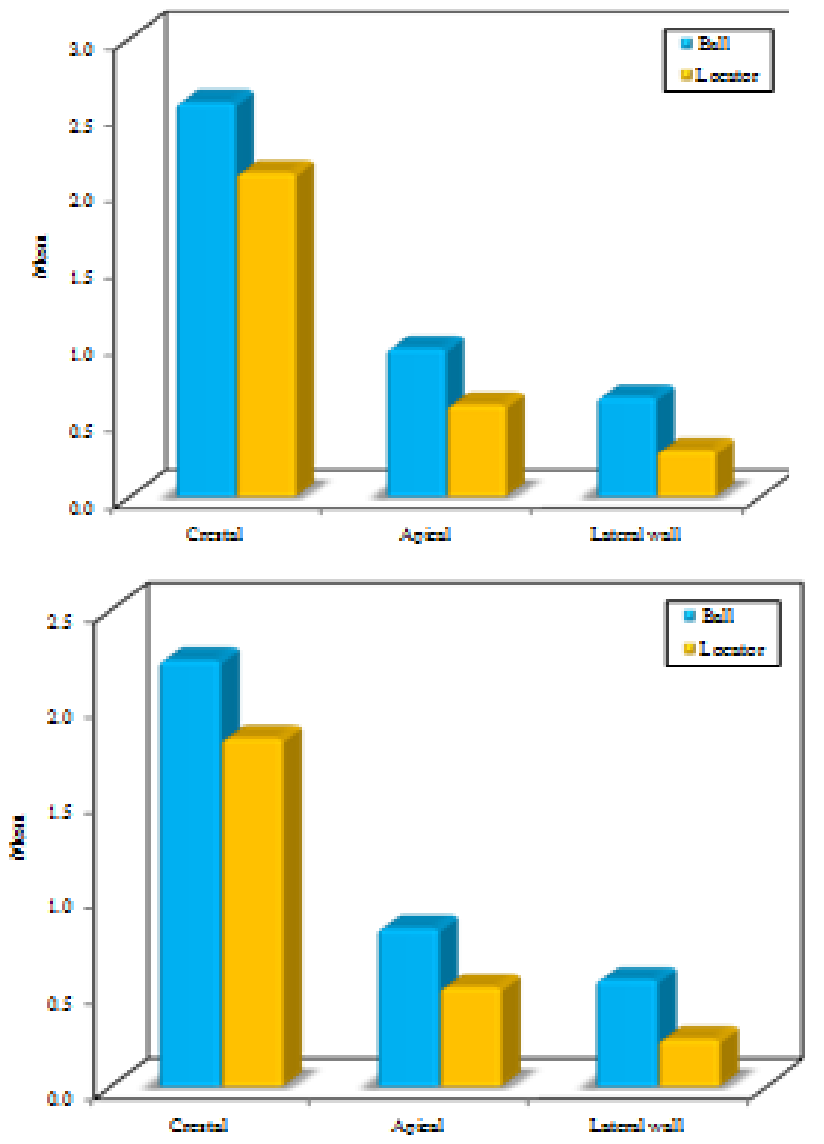

Graph 3 (a) non working side under vertical load. (b) non working side under oblique load.

Comparing resulting stresses at non working side implants when various load directions were used for both studied groups, the recorded stresses were higher when the load was vertical at all measurement sites; crestal, apical, or lateral walls of peri-implant sites (Graph 4). Moreover, when comparing vertical to oblique readings, the stress values showed statistically significant differences at all measured sites.

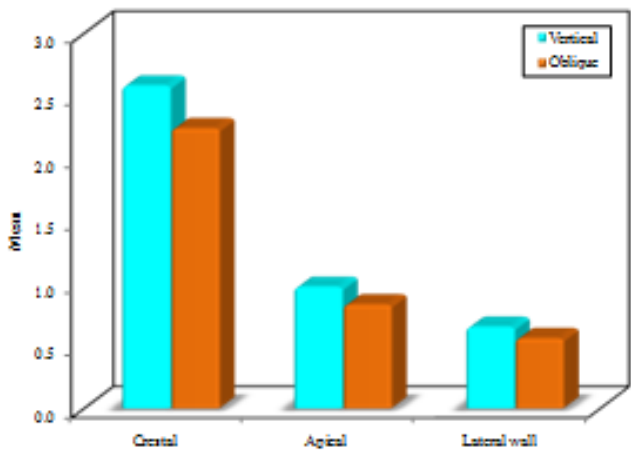




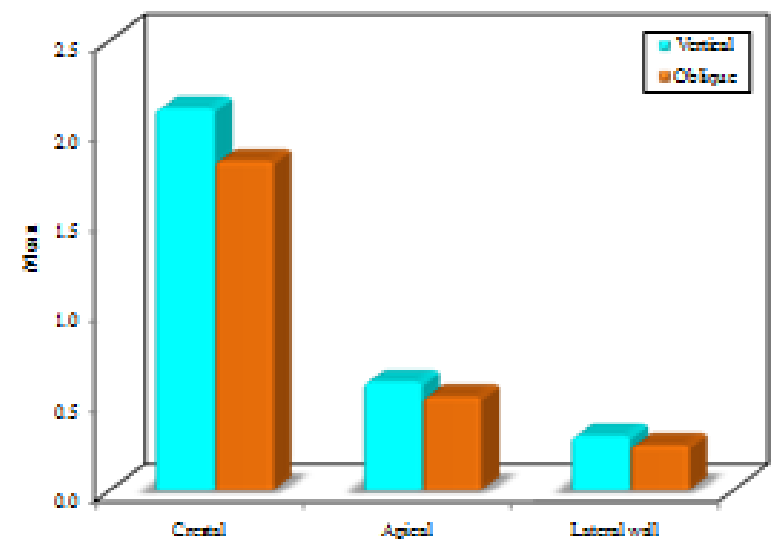

Graph 4 (a) non working side of FEM A. (b) non working side of FEM B.

\section{Comparing resulting stresses of working and non working implants when $100 \mathrm{~N}$ load was applied}

For both studied groups, the recorded stresses were higher at working side at all measurement sites; crestal, apical or lateral walls of peri-implant sites (Graph $5 \& 6$ ). The resulting stress values at the crestal bone on the non working sides were about half that of the working sides. In addition, the stress values showed statistically significant differences when working and non working sides were compared.
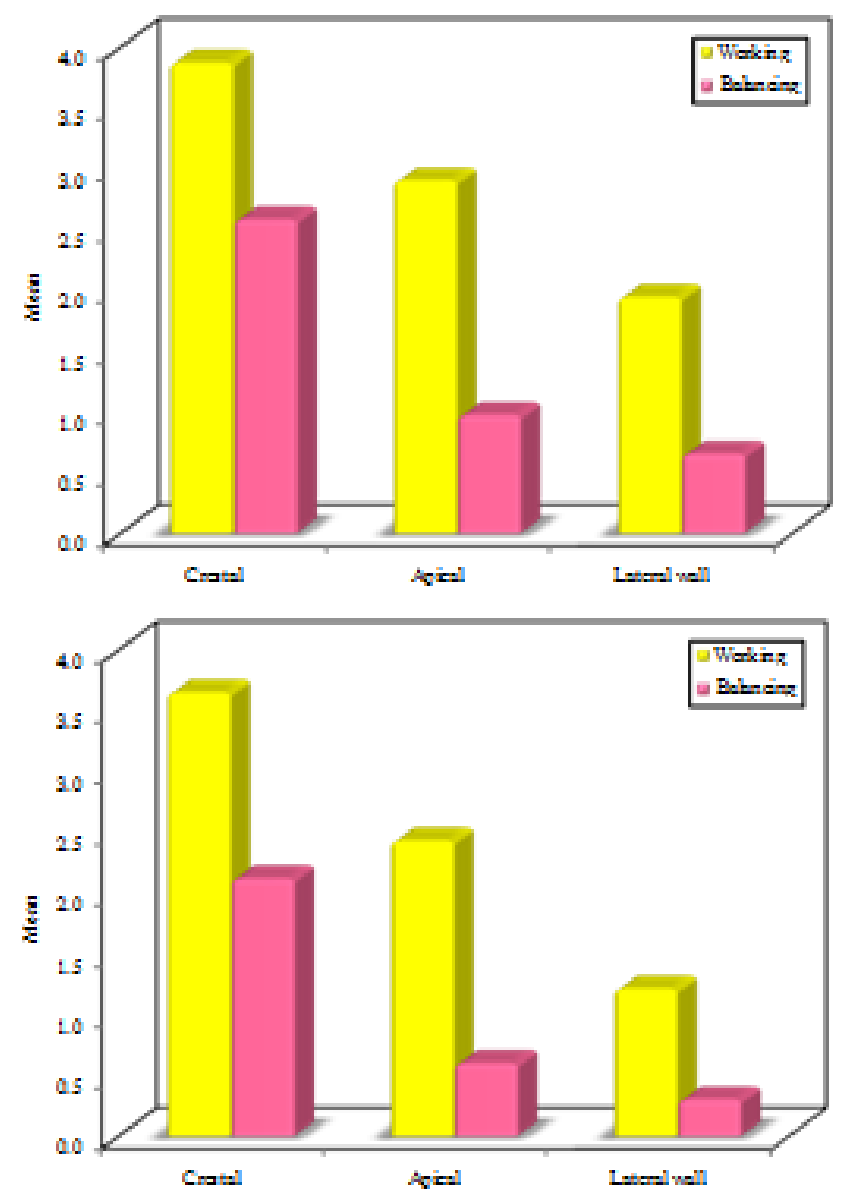

Graph 5 (a) FEM A under vertical load. (b) FEM B under vertical load.
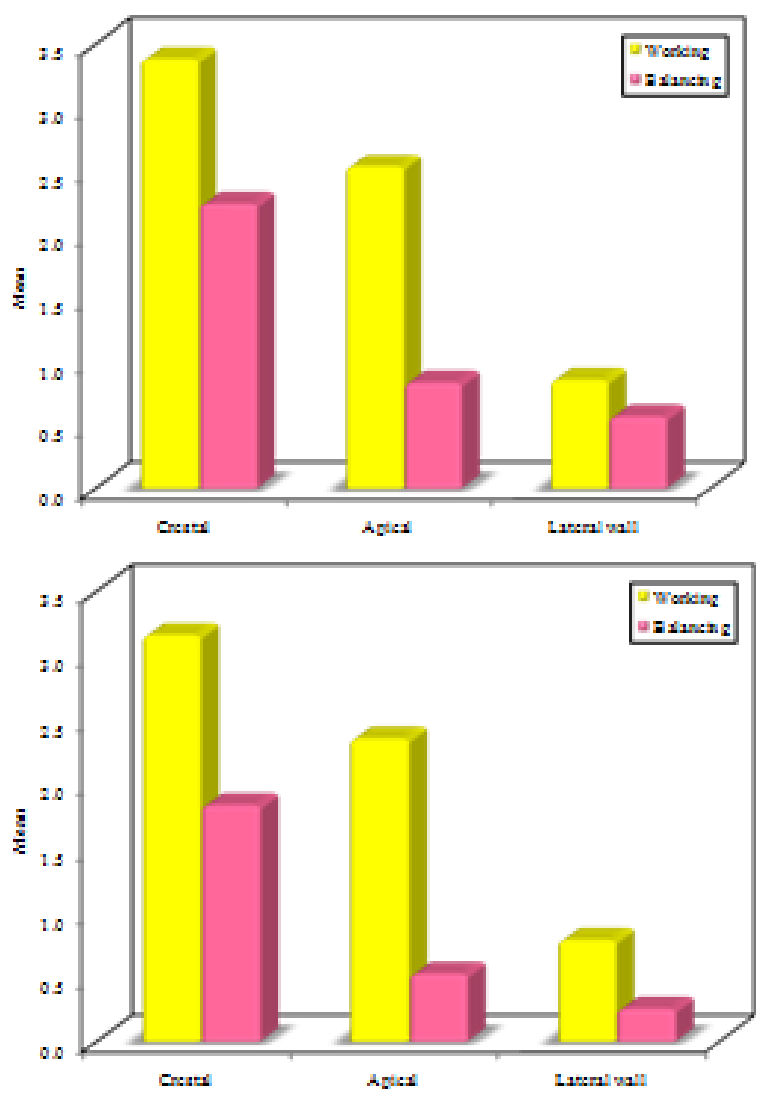

Graph 6 (a) FEM A under oblique load. (b) FEM B under oblique load.

Analysis of resulting stresses of both attachment models around the metal housings

For both studied groups, the recorded stresses were highest in value at the working side. The resulting stress values of the non working side were almost one fourth that of the working side. The difference between working and non working sides was statistically significant for both attachments while it was insignificant when comparing both attachments to each other (Graph 7). The sites at which maximum stress values were recorded are: for group [A], the most occlusal line angle of the metal housing (Figure 11), while for group [B], the lateral sides of the metal housing (Figure 12).

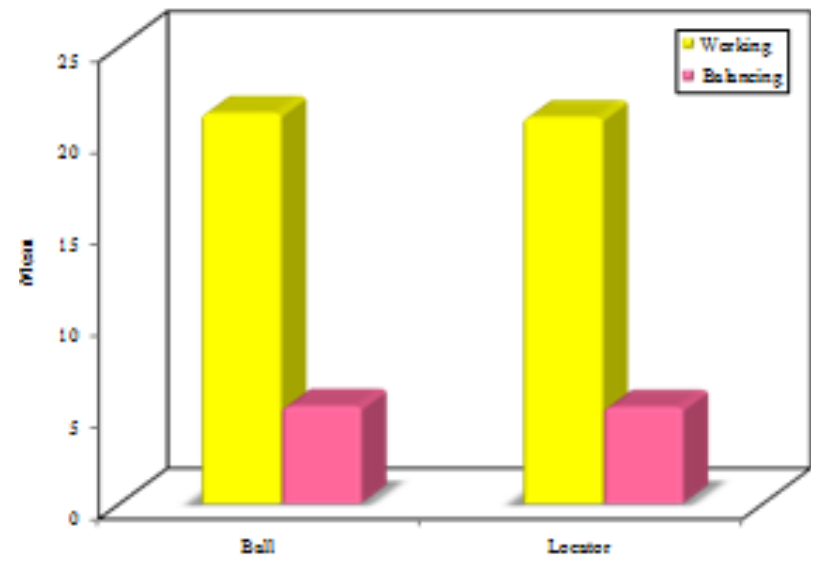

Graph 7 working and non working side metal housing stress when 100 N/ $\mathrm{mm}^{2}$ load was applied. 


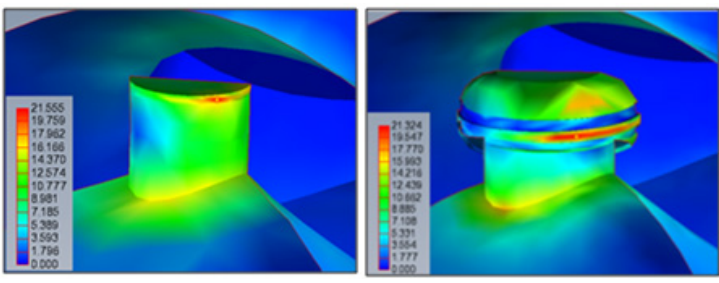

Figure I I Von Mises of working side metal housings.

\section{Analysis of interaction of all variables on resulting stresses}

Table 3 shows a two way ANOVA of all studied variables; load direction, type of attachment, working or non working side, and

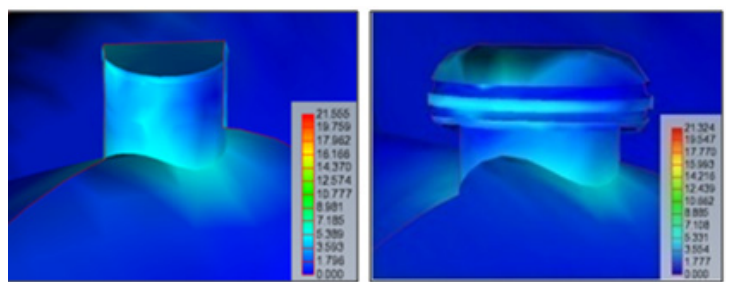

Figure I 2 Von Mises of non working side metal housings.

location within each peri-implant site. The test revealed that all variables under study have a significant effect on the resulting stresses around the implants.

Table 3 Two way ANOVA test to analyze the interaction of all variables under study on resulting stresses

\begin{tabular}{|c|c|c|c|c|c|}
\hline & Sum of Squares & df & Mean Square & $\mathbf{F}$ & $\mathbf{P}$ \\
\hline Ball/Locator & 4.248 & I & 4.248 & $130.020 *$ & $<0.001 *$ \\
\hline Crestal/Apical/Lateral wall & 100.486 & 2 & 50.243 & I537.907* & $<0.00 I^{*}$ \\
\hline $\begin{array}{l}\text { Vertical/Oblique * Ball/Locator *Working/Non } \\
\text { working * Location }\end{array}$ & 9.864 & 18 & 0.548 & $16.774 *$ & $<0.001 *$ \\
\hline Error & 3.920 & 120 & - & - & - \\
\hline Total & 634.143 & 144 & - & - & - \\
\hline
\end{tabular}

\section{Discussion}

The results of stress analysis when comparing both studied attachments at various peri-implant sites demonstrated generally that the highest values were found at the bone crest followed by apical bone and lastly the lateral walls of the peri-implant site. The results of location of maximum stress values are in line with those demonstrated maximum stresses occurring at crestal bone. ${ }^{8,21-23}$ Although the crestal stress values were lower for locator attachment, the results were not always of statistical significance. This insignificance could be attributed to the adverse effect of assuming that both attachments have the same nylon rubber resilience when specifying the material properties of the FEM. Anyway, this difference between both studied attachments could be attributed to difference in attachment geometry. The Locator attachment has a low profile design which played a role in dissipating occlusal loads through the abutment to the implant in a more favorable magnitude and distribution.

This result is in line with Jain et al., ${ }^{24}$ The analysis of stresses at various peri-implant sites of both studied attachments resulting from changing the direction of occlusal load demonstrated an obvious change in load distribution around the implants given that crestal bone stresses were still the highest in magnitude. A statistically significant higher stress values were recorded when vertical $100 \mathrm{~N}$ load was applied. This result seemed to be opposite to those published by Meijer et al., ${ }^{21}$ Luo et al., ${ }^{25,26}$ These conflicting results are suggested to be due to the use of the overdenture to load the implants in this study, while many of published studies mentioned applied the loads directly over the implant abutments. The possible effect of applying loads through the overdenture is that it shared the applied load between the mucosal lining over the mandible as well as nylon rubber incorporated within the metal housing of each attachment assembly. It is also suggested that when applying vertical loads to an overdenture, the mucosa lining the crest of the alveolar ridge will share in support. While when an oblique load is used, the mucosa lining the crest as well as the lateral slopes of the alveolar ridge will share in support resulting in larger area to dissipate stresses; thus decreasing the value of maximum stress. This suggestion is in line with results of Sadowsky and Caputo et al., ${ }^{27}$ Barao et al., ${ }^{17}$ Daas et al., ${ }^{28}$ Another possible explanation of such a result is that the loaded surfaces in this study; through which the applied load was transferred to the implants, were the semi-anatomic denture teeth which possess multiple inclined planes. Thus when loaded in an inclined manner, the plane having the same direction of the applied load will diminish or cancel its effect resulting in lower maximum stress magnitude. As a fact, a lower oblique force when analyzed in two directions; vertical and horizontal or shearing one, may have a higher horizontal component than that of a higher absolute vertical one. That is why it is important to emphasize that stress direction and distribution are much more important than its magnitude.

The results of stress analysis comparing the working and non working peri-implant sites demonstrated that working side stresses were generally higher than those of the non working side. This is in line with Meijer et al., ${ }^{8}$ However, when comparing the maximum stress values of working and non working peri-implant sites to those of the working and non working metal housings of both attachments, it seemed that both attachment configurations dissipated loads in a way that non working side sharing in resulting stresses is increased. This can be deducted from the resulting stresses around the metal housings at the non working side which were about one fourth of the working side stress. On the contrary, this ratio increased to exceed the half when comparing the maximum stress values on the non working side to those of the working side at the level of the peri-implant sites. This sharing property could be attributed to the damping effect of the resilient nylon liners in both attachments which tend to optimize stress distribution over the implants retaining the overdenture. These results are in line with Luo et al., ${ }^{26}$ Regarding the maximum stress values location on the metal housing, it is suggested that the locator male housing produces a more favorable stress distribution which could promote the fracture resistance of the prosthesis.

The results of two way ANOVA studying the interaction of all studied variables; load direction, type of attachment, working or non 
working side, and location within each peri-implant site, revealed that all variables under study have a significant effect on the resulting stresses around the implants. In addition, the locator attachment was associated with a more favorable force distribution and magnitude.

\section{Conclusion}

Within the limitations of this study, various conclusions can be drawn. ${ }^{1}$ Regardless load direction used, the crestal bone around any implant is generally subjected to the highest stress values when loading that implant. ${ }^{2}$ Both studied attachment systems were successful in optimizing loads around dental implants. However, the Locator attachment might be selected over Ball \& Socket attachment when designing two-implant-retained mandibular overdentures since it is associated with more favorable stress magnitude and distribution. ${ }^{3}$ Implants shared more stress when vertical loads were applied through the overdenture. ${ }^{4}$ The implants nearest to the area where the load is applied will generally share higher stresses when compared to those far from the load application area. ${ }^{5}$ No specific single parameter could affect the outcomes of implant overdenture. Instead, treatment outcomes are favored when the treatment is based on optimizing all possible parameters.

\section{Acknowledgments}

None

\section{Conflicts of interest}

The author declares that there are no conflicts of interest.

\section{Funding}

None

\section{References}

1. Kenney R, Richards MW. Photoelastic stress patterns produced by implant-retained overdentures. J Prosthet Dent. 1998;80(5):559-564.

2. David R. Mandibular implant overdenture Treatment: consensus and controversy. J Prosthod. 2000;9(1):37-46.

3. Feine JS, Carlsson GE, Awad MA, et al. The McGill consensus statement on overdentures. Mandibular two-implant overdentures as first choice standard care for edentulous patients. Gerodontology. 2002;19(1):3-4.

4. Trakas T, Michalakis K, Kang K, et al. Attachment systems for implant retained overdentures: a literature review. Implant Dent. 2006;15(1):2434.

5. Feine JS, Carlsson GE, Awad MA, et al. The McGill consensus statement on over dentures. Montreal, Quebec, Canada: Int J Prosthodont. 2002;15(4):413-414.

6. Eltaftazani I, Moubarak A, El-Anwar M. Locator attachment versus ball attachment: 3-dimentional finite element study. Barcelona, Spain: 2010.

7. Geng JP, Tan KB, Liu GR. Application of finite element analysis in implant dentistry: a review of the literature. J Prosthet Dent. 2001;85(6):585-598.

8. Meijer HJ, Starmans FJ, Steen WH, et al. Loading conditions of endosseous implants in an edentulous human mandible: a three-dimensional, finiteelement study. J Oral Rehabil. 1996;23(11):757-763.

9. Nassef TM. Computer-Assisted Tissue Engineering for Dental Applications: Multi-Object Reconstruction Technique. USA: Lambert Academic Publishing. 2012;129-132.

10. Nassef TM, Solouma NH, Alkhodary M, et al. Extraction of Human Mandible Bones from Multi-Slice Computed Tomographic Data. Biomedical Engineering (MECBME), Middle East Conference, IEEE. 2011;1:260-263.
11. Voigt LJ. Uber die Bezechnung zwischen den beidem Elastizitatskonstanten isotroper Korper. Wied Ann. 1889;33:573-587.

12. Reuss A. Berechnung der Fliessgrenze von Mischkristalen auf grund der Plastizitatsbedigung fur Einkristalle. Z Angew Math Mech. 1929;9:49-58.

13. Barbier L, Vander Sloten J, Krzesinski E, et al. Finite element analysis of non-axial versus axial loading of oral implants in the mandible of dog. $J$ Oral Rehabil. 1998;25(11):847-858.

14. Menicucci G, Lorenzetti M, Pera P, et al. Mandibular implant-retained overdenture: finite element analysis of two anchorage systems. Int J Oral Maxillofac Implants. 1998;13(3):369-376.

15. Tanino F, Hayakawa I, Hirano S, et al. Finite element analysis of stressbreaking attachments on maxillary implant-retained overdentures. Int $J$ Prosthodont. 2007;20(2):193-198.

16. Brunski JB, Puleo DA, Nanci A. Biomaterials and biomechanics of oral and maxillofacial implants: current status and future developments. Int $J$ Oral Maxillofac Implants. 2000;15(1):15-46.

17. Barao VAR, Assuncao WG, Tabata LF, et al. Effect of different mucosa thickness and resiliency on stress distribution of implantretained overdentures-2D FEA. Comput Methods Programs Biomed. 2008;92(2):213-223.

18. Chun HJ, Park DN, Han CH, et al.Stress distributions in maxillary bone surrounding overdenture implants with different overdenture attachments. J Oral Rehabil. 2005;32(3):193-205.

19. Leslie E, Geoffrey J, James M. Statistical analysis. Interpretation and uses of medical statistics (4th edn), USA, Canada, Australia: Oxford Scientific Publications. 1991;411-416.

20. Kirkpatrick LA, Feeney BC. A simple guide to IBM SPSS statistics for version 20.0. (Student ed.) Belmont, California: Wadsworth, Cengage Learning. 2013;115.

21. Meijer HJ, Starmans FJ, Steen WH, et al. A three dimensional, finiteelement analysis of bone around dental implants in an edentulous human mandible. Arch Oral Biol. 1993;38(6):491-496.

22. Zhou B, Rao NJ, Yin ZJ, et al. The 3-dimentional finite elements analysis of ball attachment and telescopic crowns retained mandibular implantsurpported overdenture. Chinese J Prosthod. 2006.

23. John J, Rangarajan V, Savadi RC, et al. A finite element analysis of stress distribution in the bone, around the implant supporting a mandibular overdenture with ball/o ring and magnetic attachment. $J$ Indian Prosthodont Soc. 2012;12(1):37-44.

24. Jain S, Jain D, Kumar A. Comparative evaluation of stress in canine retained mandibular overdentures with three attachment designs - a 3D finite element analysis. JIDA. 2011;5:791-793.

25. Luo X, Ouyang G, Ma X, et al. The three-dimensional analysis of mandibular overdenture supported by implants. Sheng Wu, Yi Xue, Gong Cheng, editors.1998;15(2):167-171.

26. Luo X, Ouyang G, Ma X. Three dimensional finite element analysis on the mandibular complete overdenture supported by nature roots or implants. Zhonghua Kou, Qiang Yi Xue, Za Zhi, editors. 1998;33(5):303-305.

27. Sadowsky SJ, Caputo AA. Effect of anchorage systems and extension base contact on load transfer with mandibular implant-retained overdentures. $J$ Prosthet Dent. 2000;84(3):327-334.

28. Daas M, Dubois G, Bonnet AS, et al. A complete finite element model of a mandibular implant-retained overdenture with two implants: Comparison between rigid and resilient attachment configurations. Med Eng Phys. 2008;30(2):218-225. 